\title{
Depth of pupation and survival of the Oriental fruit fly, Bactrocera dorsalis (Diptera: Tephritidae) pupae at selected soil moistures
}

\author{
Bohua Hou, Qi XIE and Runjie ZHANG* \\ State Key Laboratory for Biocontrol/Institute of Entomology, Sun Yat-Sen University; Guangzhou 510275, P. R .China
}

(Received 14 December 2005; Accepted 24 May 2006)

\begin{abstract}
Estimates of pupation depth and survival of the Oriental fruit fly, Bactrocera dorsalis (Hendel), are important for optimizing soil control and for better understanding its natural mortality in the agricultural system of Guangzhou, China. Late third-instar larvae were placed in soils having relative moistures of $0-100 \%$ for pupation. No pupae were found on the surface at soil moistures of $0-70 \%$. Instead, more than $50 \%$ of the larvae pupated on the surface at soil moistures of 80,90 , and $100 \%$. Most of the larvae preferred to pupate in less than $4 \mathrm{~cm}$ of the soils, while relatively few larvae moved more than $4 \mathrm{~cm}$ when the soils received too little water or too much water. The survival rate of pupae at $70 \%$ moisture level was low, and the pupae were unable to survive at soil moistures of $0,80,90$, and $100 \%$, while emergence rates exceeded $90 \%$ at the conditions of 10-60\% moisture levels. Moreover, soil moistures had an influence on the average time to emergence (average time between the larvae release and the emergence of adults). Adult flies at 30\% moisture level emerged earlier than those at the other moisture levels, whereas the average time to emergence at $70 \%$ moisture level was the longest.
\end{abstract}

Key words: Bactrocera dorsalis; pupation depth; survival; average time to emergence; soil moisture

\section{INTRODUCTION}

Oriental fruit fly, Bacrocera dorsalis (Hendel), is one of the most destructive fruit fly pests in East Asia and the Pacific, and occurs on a wide range of fruit crops (Allwood et al., 1999). It is considered as a government regulatory agent by a large number of countries for the economic loss caused by this species, and becomes a major barrier to trade and economic development (Aluja and Liedo, 1993).

Oriental fruit fly females insert their eggs beneath the skin of suitable hosts, especially in ripening or ripe fruits and vegetables. The larvae shed their skin twice as they feed and grow. At completion of third instar, the larvae abandon the fruit. After a brief dispersal period, the larvae burrow into the soil and pupate. When the metamorphosis is complete, teneral adults burrow upward to the soil surface, where they harden their wings before takeoff (Smith, 1989).

Because of their peculiar life history, most of the efforts in fruit fly control and eradication have focused on mature adults, e.g., bait traps (Vargas et al., 2003; McQuate et al., 2005), methyl eugenol utilizing (Cunningham, 1989; Shelly et al., 2004) and sterile insect technique (Wong et al., 1992; Hendrichs et al., 2002). However, some attention has been paid to the possibility of fly control by targeting late-instar larvae and pupae. Stark et al. (1990) indicated that azadirachtin prevents the eclosion of three tephritid species, Ceratitis capitata (Wiedemann), Bactrocera cucurbitae Coquillett and $B$. dorsalis. Entomopathogenic nematodes provide yet another possibility to suppress fruit fly populations by reducing the number of late instars in soil. During field tests in Hawaii, drench applications of Steinernema feltiae Filipjiv to the soil increased the mortality of Mediterranean fruit fly larvae by $99.5 \%$ (Lindegren et al., 1990).

Exposure to unfavorable environmental conditions during pupation is known to have a negative effect on the survival of tephritid fruit flies (Vargas et al., 1987; Eskafi and Fernandez, 1990; Hen-

\footnotetext{
* To whom correspondence should be addressed at: E-mail: 1s11@zsu.edu.cn DOI: $10.1303 / \mathrm{aez} .2006 .515$
} 
nessey, 1994; Jackson et al., 1998). Water balance plays an important role in the pupal stage of the Oriental fruit fly, but not much research has been done regarding the influence of soil moisture on the survival of this species.

Knowledge of pupation behavior of the Oriental fruit fly is necessary for implementation of soil control methods, and exploring the influence of soil moisture on the survival of this species may help to estimate its natural mortality. The objective of the present study was to determine the depth of pupation and mortality of pupae with respect to various soil moistures at local soil conditions.

\section{MATERIALS AND METHODS}

Larvae culture. B. dorsalis was obtained from the mass-rearing stock maintained at the Institute of Entomology, Sun Yat-Sen University, Guangzhou, China. The procedures for fly rearing and maintenance were described by Mei and Zhou (1995). Third-instar larvae (6-7 d old after hatching), and those which had reached the jumping stage, were collected and used in the experiments.

Pupation medium. Soil was acquired from Luntou Orchard, Guangzhou suburb, Guangdong province $\left(\mathrm{E} 113^{\circ} 17^{\prime}, \mathrm{N} 23^{\circ} 8^{\prime}\right)$. Soil samples were collected from $0-15 \mathrm{~cm}$ depths of the garden. Before being placed in the containers, the soil was sieved through a $1 \times 1 \mathrm{~cm}$ sieve and then dried in an oven for $48 \mathrm{~h}$ at $100^{\circ} \mathrm{C}$. Soil property and the percentage of water saturation were analyzed as $32.5 \%$ sand, $40.7 \%$ silt, $26.8 \%$ clay, and $65.1 \%$ field capacity.

Pupation device. The test containers were made from clear plastic cups $12.0 \mathrm{~cm}$ high, having a top opening with a diameter of $7.5 \mathrm{~cm}$, and a solid bottom with a diameter of $5.0 \mathrm{~cm}$. The top opening was covered with gauze mesh glued shut, to prevent the larvae from escaping.

Influence of soil moistures on depth of pupation. Soils were wetted with tap water to relative moisture gradients of $0,10,20,30,40,50,60,70$, 80,90 and $100 \%$ respectively (the soils were stirred with 10, 20 and 30\% moisture levels to uniformity). Target soils as pupation medium were added to the brim of the containers then gently compacted and smoothed in each container by pushing an empty cup down inside the one filled with soil.
The experiment was designed to have 11 moisture treatments $\times 30$ larvae per replication $\times 4$ replications. The containers were marked with numbers and their target moistures, and arranged randomly in an environmental chamber at $26 \pm 2{ }^{\circ} \mathrm{C}, 70 \pm 5 \%$ $\mathrm{RH}$, and $12: 12$ (L:D) h photoperiod.

After $48 \mathrm{~h}$, the distribution of pupation depth was checked. First, the number of pupae on the surface was recorded. Then the soil and the plastic were removed by a scalpel in successive $2 \mathrm{~cm}$ layers. Each layer was sifted through a $2 \times 2 \mathrm{~mm}$ sieve with tap water to separate the pupae from soil, and the number of pupae within each layer was recorded.

In the primary observation, some larvae in certain containers, especially in containers with high moisture levels were unable to pupate in $48 \mathrm{~h}$. These un-pupated larvae also were treated as "pupae". Namely, the pupation rate was assumed to be $100 \%$.

Influence of soil moistures on pupal survival. Experimental designs were similar to those described above, but this time every container was marked with not only target moisture level but also with its weight. After the release of the third-instar larvae, containers were examined every $48 \mathrm{~h}$, and tap water was added to the soil surface with an injector consistently until target moisture levels were reached. Meanwhile, containers were examined every $24 \mathrm{~h}$, and adult flies that emerged from pupae in each container were recorded and then removed until no flies emerged.

Statistical analysis. The number of pupae from each depth level was converted into percentages. The data were normalized by an arcsine square root transformation and analyzed by a one-way ANOVA, followed by a Tukey test, to compare differences among the various treatments at the $\alpha=0.05$ level, using SPSS 13.0 for Windows (SPSS Inc., Chicago).

Data on adult eclosion rates at each observation time interval were calculated. Additionally, average time to emergence (average time between the larvae release and the emergence of adults) at each treatment was calculated using the formula: $D=\left(n_{1} d_{1}+n_{2} d_{2}+\cdots+n_{i} d_{i}\right) /\left(n_{1}+n_{2}+\cdots+n_{i}\right)$, where $D$ represents the average time to emergence, $n_{i}$ is the emergence number, and $d_{i}$ is the observation time. Arcsine square root transformation was applied to adult emergence rates prior to analysis. 
Table 1. Depth of pupation of the Oriental fruit fly in soils at various moistures

\begin{tabular}{ccccccc}
\hline \multirow{2}{*}{$\begin{array}{c}\text { Moisture } \\
\text { levels (\%) }\end{array}$} & \multicolumn{5}{c}{ Depth levels (successive $2 \mathrm{~cm}$ depth from the soil surface) } \\
\cline { 2 - 7 } & Surface & $0-2 \mathrm{~cm}$ & $2-4 \mathrm{~cm}$ & $4-6 \mathrm{~cm}$ & $6-8 \mathrm{~cm}$ & $8-10 \mathrm{~cm}$ \\
\hline 0 & $0.0 \pm 0.0 \mathrm{~b}$ & $65.0 \pm 6.9 \mathrm{~cd}$ & $24.2 \pm 7.4 \mathrm{bc}$ & $10.8 \pm 1.7 \mathrm{a}$ & $0.0 \pm 0.0 \mathrm{~b}$ & $0.0 \pm 0.0 \mathrm{~b}$ \\
10 & $0.0 \pm 0.0 \mathrm{~b}$ & $45.8 \pm 8.3 \mathrm{def}$ & $44.2 \pm 7.9 \mathrm{a}$ & $10.0 \pm 2.7 \mathrm{a}$ & $0.0 \pm 0.0 \mathrm{~b}$ & $0.0 \pm 0.0 \mathrm{~b}$ \\
20 & $0.0 \pm 0.0 \mathrm{~b}$ & $60.0 \pm 6.1 \mathrm{de}$ & $34.2 \pm 6.3 \mathrm{ab}$ & $5.8 \pm 3.2 \mathrm{~b}$ & $0.0 \pm 0.0 \mathrm{~b}$ & $0.0 \pm 0.0 \mathrm{~b}$ \\
30 & $0.0 \pm 0.0 \mathrm{~b}$ & $83.3 \pm 6.1 \mathrm{bc}$ & $15.8 \pm 5.0 \mathrm{cde}$ & $0.8 \pm 1.7 \mathrm{~cd}$ & $0.0 \pm 0.0 \mathrm{~b}$ & $0.0 \pm 0.0 \mathrm{~b}$ \\
40 & $0.0 \pm 0.0 \mathrm{~b}$ & $81.7 \pm 6.4 \mathrm{bc}$ & $18.3 \pm 6.4 \mathrm{~cd}$ & $0.0 \pm 0.0 \mathrm{~d}$ & $0.0 \pm 0.0 \mathrm{~b}$ & $0.0 \pm 0.0 \mathrm{~b}$ \\
50 & $0.0 \pm 0.0 \mathrm{~b}$ & $87.5 \pm 4.2 \mathrm{ab}$ & $12.5 \pm 4.2 \mathrm{cde}$ & $0.0 \pm 0.0 \mathrm{~d}$ & $0.0 \pm 0.0 \mathrm{~b}$ & $0.0 \pm 0.0 \mathrm{~b}$ \\
60 & $0.0 \pm 0.0 \mathrm{~b}$ & $93.3 \pm 4.7 \mathrm{ab}$ & $6.7 \pm 4.7 \mathrm{de}$ & $0.0 \pm 0.0 \mathrm{~d}$ & $0.0 \pm 0.0 \mathrm{~b}$ & $0.0 \pm 0.0 \mathrm{~b}$ \\
70 & $0.0 \pm 0.0 \mathrm{~b}$ & $95.8 \pm 4.2 \mathrm{a}$ & $4.2 \pm 4.2 \mathrm{e}$ & $0.0 \pm 0.0 \mathrm{~d}$ & $0.0 \pm 0.0 \mathrm{~b}$ & $0.0 \pm 0.0 \mathrm{~b}$ \\
80 & $54.2 \pm 5.7 \mathrm{a}$ & $39.2 \pm 3.2 \mathrm{ef}$ & $6.7 \pm 3.8 \mathrm{de}$ & $0.0 \pm 0.0 \mathrm{~d}$ & $0.0 \pm 0.0 \mathrm{~b}$ & $0.0 \pm 0.0 \mathrm{~b}$ \\
90 & $54.2 \pm 9.9 \mathrm{a}$ & $31.7 \pm 5.8 \mathrm{f}$ & $7.5 \pm 3.2 \mathrm{de}$ & $4.2 \pm 1.7 \mathrm{bc}$ & $2.5 \pm 1.7 \mathrm{a}$ & $0.0 \pm 0.0 \mathrm{~b}$ \\
100 & $61.7 \pm 4.3 \mathrm{a}$ & $21.7 \pm 4.3 \mathrm{f}$ & $5.8 \pm 1.7 \mathrm{de}$ & $5.0 \pm 1.9 \mathrm{~b}$ & $3.3 \pm 2.7 \mathrm{a}$ & $2.5 \pm 3.2 \mathrm{a}$ \\
\hline
\end{tabular}

Each value represents mean percentage (mean \pm SD) of four replicates. Means in the same column followed by the same letter are not significantly different $(p>0.05)$ using Tukey test.

Similar analysis was conducted to test for variation in eclosion rates and average time to emergence among the various treatments.

\section{RESULTS}

The depth of pupation was significantly affected by the moisture percentage of the pupation substrate (Table 1). There were no pupae found on the surface at soil moistures of $0-70 \%$, whereas, on average, $54.2-61.7 \%$ larvae pupated on the surface at soil moistures of $80-100 \%$. Larvae pupated in 0 $2 \mathrm{~cm}$ depth ranged from $21.7 \%$ to $95.8 \%$ with the difference among these treatments being highly significant, especially, larvae were fewer at 80-100\% moisture levels $\left(F_{10,33}=34.6, p<0.001\right)$. Almost all the larvae pupated in less than $4 \mathrm{~cm}$ at soil moistures of $30-80 \%$, while relatively few larvae selected the depth of more than $4 \mathrm{~cm}$ at the other soil moisture levels.

Pupae successfully completed their development at soil moistures of $10-70 \%$, whereas no adult emerged at soil moistures of $0,80,90$ and $100 \%$. Nine days after larval release, adult flies emerged only in the containers with 20,30 and $40 \%$ moisture levels, moreover, the eclosion rate at $30 \%$ moisture level was $49.2 \%$, which was higher than those at the other moisture levels $\left(F_{6,21}=407.2\right.$, $p<0.001)$. Ten days after larval release, the majority of pupae eclosed at the soil moistures of 10, 20, 40,50 and $60 \%$, while there were $48.3 \%$ and $20.0 \%$ adult flies emerging at $30 \%$ and $70 \%$ mois- ture levels respectively. Eleven days after larval release, pupae at 10-60\% moisture levels completed their eclosion, while an eclosion rate of $13.3 \%$ was observed at the $70 \%$ moisture level. Additionally, an emergence rate of $12.5 \%$ remained at the $70 \%$ moisture level until $12 \mathrm{~d}$ after larval release. The total eclosion rate ranged from $45.8 \%$ to $98.3 \%$, and flies emerging at the $70 \%$ moisture level were fewer than those at the other moisture levels $\left(F_{6,21}=29.3, p<0.001\right)$ (Table 2).

Moreover, average time to emergence varied significantly among the moisture levels $\left(F_{6,21}=161.3\right.$, $p<0.001)$. Average time to emergence ranged from $9.5 \mathrm{~d}$ to $10.8 \mathrm{~d}$ among the treatments. Adult flies at $30 \%$ moisture levels emerged earlier than those at the other moisture levels, whereas the average time to emergence at the $70 \%$ moisture level was the longest in the experiment (Table 2).

\section{DISCUSSION}

Tephritid fruit flies' activity often tracks moisture gradients. Hennessey (1994) found that the Caribbean fruit fly, Anastrepha suspensa (Loew), pupated in the upper few centimeters between $0.7 \mathrm{~cm}$ and $3.3 \mathrm{~cm}$. In Mexico agricultural habitats, pupae of fruit fly, Anastrepha spp. were discovered at a depth less than $5 \mathrm{~cm}$ and none were found on the surface (Hodgson et al., 1998). Ibrahim and Mohamad (1978) determined that B. dorsalis pupate at $2-3 \mathrm{~cm}$ soil depth in moist, sandy loam in the laboratory. Alyokhin et al. (2001) discovered 
Table 2. Eclosion rate and average time to emergence (average time between the larvae release and the emergence of adults) of the Oriental fruit fly in soils at various moistures

\begin{tabular}{crrrrrr}
\hline \multirow{2}{*}{$\begin{array}{c}\text { Moisture levels } \\
(\%)\end{array}$} & \multicolumn{3}{c}{ Eclosion rates (\%) } & & Average time to \\
\cline { 2 - 7 } & $9 \mathrm{~d}$ & $10 \mathrm{~d}$ & $11 \mathrm{~d}$ & $12 \mathrm{~d}$ & Total & $\begin{array}{c}\text { Amergence }(\mathrm{d}) \\
\text { em }\end{array}$ \\
\cline { 2 - 7 } 10 & $0.0 \pm 0.0 \mathrm{c}$ & $87.5 \pm 3.2 \mathrm{~b}$ & $5.0 \pm 4.3 \mathrm{~b}$ & $0.0 \pm 0.0 \mathrm{~b}$ & $92.5 \pm 3.2 \mathrm{a}$ & $10.1 \pm 0.1 \mathrm{~b}$ \\
20 & $9.2 \pm 3.2 \mathrm{~b}$ & $82.5 \pm 4.2 \mathrm{~b}$ & $2.5 \pm 1.7 \mathrm{~b}$ & $0.0 \pm 0.0 \mathrm{~b}$ & $94.2 \pm 3.2 \mathrm{a}$ & $9.9 \pm 0.1 \mathrm{~b}$ \\
30 & $49.2 \pm 3.2 \mathrm{a}$ & $48.3 \pm 3.3 \mathrm{c}$ & $0.0 \pm 0.0 \mathrm{~b}$ & $0.0 \pm 0.0 \mathrm{~b}$ & $97.5 \pm 3.2 \mathrm{a}$ & $9.5 \pm 0.0 \mathrm{c}$ \\
40 & $5.0 \pm 1.9 \mathrm{~b}$ & $84.2 \pm 3.2 \mathrm{~b}$ & $5.0 \pm 3.3 \mathrm{~b}$ & $0.0 \pm 0.0 \mathrm{~b}$ & $94.2 \pm 1.7 \mathrm{a}$ & $10.0 \pm 0.1 \mathrm{~b}$ \\
50 & $0.0 \pm 0.0 \mathrm{c}$ & $95.8 \pm 1.7 \mathrm{a}$ & $2.5 \pm 1.7 \mathrm{~b}$ & $0.0 \pm 0.0 \mathrm{~b}$ & $98.3 \pm 1.9 \mathrm{a}$ & $10.0 \pm 0.0 \mathrm{~b}$ \\
60 & $0.0 \pm 0.0 \mathrm{c}$ & $95.8 \pm 4.2 \mathrm{a}$ & $0.8 \pm 1.7 \mathrm{~b}$ & $0.0 \pm 0.0 \mathrm{~b}$ & $96.7 \pm 2.7 \mathrm{a}$ & $10.0 \pm 0.0 \mathrm{~b}$ \\
70 & $0.0 \pm 0.0 \mathrm{c}$ & $20.0 \pm 2.7 \mathrm{~d}$ & $13.3 \pm 2.7 \mathrm{a}$ & $12.5 \pm 3.2 \mathrm{a}$ & $45.8 \pm 3.2 \mathrm{~b}$ & $10.8 \pm 0.1 \mathrm{a}$ \\
\hline
\end{tabular}

Each value represents mean (mean $\pm \mathrm{SD}$ ) of four replicates. Means in the same column followed by the same letter are not significantly different $(p>0.05)$ using Tukey test. $9 \mathrm{~d}, 10 \mathrm{~d}, 11 \mathrm{~d}$ and $12 \mathrm{~d}$ represent the days after the larvae release.

that the majority of $B$. dorsalis larvae pupated within the upper $4 \mathrm{~cm}$ depth in soil. A similar trend has been observed in this study, with no pupae being found on the surface and majority of the species preferring to pupate at less than $4 \mathrm{~cm}$ depth when the soil moisture ranged from $0 \%$ to $70 \%$. An attempt to avoid adverse climatic factors or biological conditions during the pupal stage may explain this trend, since substantial predation on pupae of this species by predators was reported (Hodgson et al., 1998).

We detected that some larvae pupated at more than $4 \mathrm{~cm}$ in soil with no water, while Jackson et al. (1998) observed that most pupae of the Oriental fruit fly occurred at a depth of $0-5.5 \mathrm{~mm}$ in dry sand (no water). The differences between the two studies may be attributed to the different pupation media. Additionally, a few larvae pupated at more than $4 \mathrm{~cm}$ in soils having 10 and $20 \%$ moisture levels. We suggest that there was little water available for pupal development. Larvae went deeper into the soil to seek more water.

Moreover, over $50 \%$ of the larvae pupated on the surface, and relatively few larvae pupated far deeper when the soil moistures ranged from $80 \%$ to $100 \%$. An alternative explanation for the random distribution might be that high water content posed a risk to their survival. Larvae attempt to seek suitable pupation sites to accommodate themselves.

Influences of soil water content on the development of this species have not been clearly defined, although a study by Alyokhin et al. (2001) indicated that $B$. dorsalis prefer to pupate in moist soil rather than dry soil. In fact, there are only two moisture gradients in their study, as they defined soil as "moist" when it reached a relative saturation of $58 \%$ and "dry" if it had a relative saturation of $27 \%$ (Alyokhin et al., 2001). Actually, mortality of fruit-infesting Tephritids was affected not only by the soil moisture but also by pupation medium and other determining factors (Eskafi and Fernandez, 1990; Hennessey, 1994). The results suggest that the survival of the larva-pupal stage might be inhibited when the soil moisture reached $70 \%$. It is likely that the larvae and/or pupae will be killed if they stay in the soils with high moisture levels, since the field capacity $(65.1 \%)$ of the soils used in our experiment is high. Meanwhile, we found that the pupae failed to survive in soils that received no water or too much water, which coincides with the observations by Serit and Tan (1990), who found that $77.8 \%$ of the mortality incurred during the life cycle of $B$. dorsalis in Penang, Malaysia, was because of desiccation or drowning of larvae and pupae in soil.

Furthermore, the results show that pupae at the $30 \%$ moisture level emerged earlier than those at the other moisture levels. In order to mix the soil and water to uniformity, soils at 10, 20 and $30 \%$ moisture levels need to be stirred in our experimental process. In this process, soil physical properties were influenced, as the pore size increases and the bulk density decreases. This may facilitate the pupae to burrow upward to the soil surface. Why didn't this trend show up at the 10 and 20\% moisture levels? A reasonable explanation for the case might be that there is little water available for 
the development of pupae. This may delay their eclosion. As a matter of fact, according to laboratory observation, the adult flies that emerged at $10 \%$ and $20 \%$ moisture levels declined in vigor.

On the basis of the results achieved, it can be concluded that $B$. dorsalis prefer to pupate within the $4 \mathrm{~cm}$ depth. It is likely that the distribution of the pupae in natural habitats will be clumped. This is an important consideration in developing a sampling and control technique for pupal populations of this pest. For example, the cost-efficiency of insecticide or nematode application can be increased significantly if the pupae were maintained at an appropriate depth. In addition, we learn that pupae will be exposed to the soil surface through agricultural operations like ploughing and hoeing the stirred and scraped soil up to the depth of about $4 \mathrm{~cm}$. In this way, a large number of the immature stages could normally be killed by adverse climatic factors or biological conditions. The results show that the immature stage development of this pest was inhibited when the soils received too much water, suggesting that drench application in fields may be another consideration in suppressing the populations. Moreover, the duration of the pupal stage in the present study indicates that all the controls or treatments should be taken done at appropriate times. However, we did not identify the influence of other environmental factors on the pupal behaviour and survival. Further investigations under field conditions should be carried out to achieve a better understanding of these issues.

\section{ACKNOWLEDGEMENTS}

This work was supported by the National Grand Fundamental Research "973" Program of China (grant No. 2002CB111405), the National Nature Science Foundation of China (grant No. 30471162), and the National Nature Science Foundation of Guangdong Province (grant No. 05003324).

\section{REFERENCES}

Allwood, A. J., A. Chinajariyawong, R. A. I. Drew, E. L. Hamacek, D. L. Hancock, C. Hengsawad, J. C. Jinapin, M. Jirasurat, C. K. Krong, S. Kritsaneepaiboon, C. T. S. Leong and S. Vijaysegaran (1999) Host plant records for fruit flies (Diptera: Tephritidae) in South East Asia. Raffles Bull. Zool. Suppl. 7: 1-92.

Aluja, M. and P. Liedo (eds.) (1993) Fruit Flies, Biology and Management. Springer-Verlag, New York, USA. 492 pp.

Alyokhin, A. V., C. Mille, R. H. Messing and J. J. Duan (2001) Selection of pupation habitats by Oriental fruit fly larvae in the laboratory. J. Insect Behav. 14: 57-67.

Cunningham, R. T. (1989) Control; insecticides; male annihilation. In World Crop Pests. Vol. 3(B). Fruit Flies: Their Biology, Natural Enemies and Control (A. S. Robinson and G. Hooper eds.). Elsevier, Amsterdam, Netherlands, pp. 345-351.

Eskafi, F. M. and A. Fernandez (1990) Larvae-pupal mortality of Mediterranean fruit fly (Diptera: Tephritidae) from interaction of soil, moisture, and temperature. Environ. Entomol. 19: 1666-1670.

Hendrichs, J., A. S. Robinson, J. P. Carol and W. Enkerlin (2002) Medfly areawide sterile insect technique programmes for prevention, suppression on eradication: the importance of mating behaviour studies. Fla. Entomol. 85: $1-13$.

Hennessey, M. K. (1994) Depth of pupation of Caribbean fruit fly in soils in the laboratory. Environ. Entomol. 23: 1119-1123.

Hodgson, P. J., J. M. Sivinski, G. Quintero and M. Aluja (1998) Depth of pupation and survival of fruit fly (Anastrepha spp.: Tephritidae) pupae in a range of agricultural habitats. Environ. Entomol. 27: 1310-1314.

Ibrahim, Y. and R. Mohamad (1978) Pupal distribution of Dacus dorsalis Hendel in relation to host plants and its pupation depth. Pertanika 1: 66-69.

Jackson, C. G., J. P. Long and L. M. Klungness (1998) Depth of pupation in four species of fruit flies (Diptera: Tephritidae) in sand with and without moisture. J. Econ. Entomol. 91: 138-142.

Lindegren, J. E., T. T. Wong and D. O. McInnis (1990) Response of Mediterranean fruit fly (Diptera: Tephritidae) to the entomogenous nematode Steinernema feltiae in field tests in Hawaii. Environ. Entomol. 19: 383-386.

McQuate, G. T., S. L. Peck, P. G. Barr and C. D. Sylva (2005) Comparative evaluation of spinosad and phloxine $\mathrm{B}$ as toxicants in protein baits for suppression of three fruit fly (Diptera: Tephritidae) species. J. Econ. Entomol. 98: 1170-1178.

Mei, L. and C. Zhou (1995) Influence of intro-specific competition on population dynamics of Bactrocera dorsalis (Hendel). Supplement to the Journal of Sun Yatsen University 2: 41-46 (in Chinese with English summary).

Serit, M. and K. H. Tan (1990) Immature life table of a natural population of Dacus dorsalis in a village ecosystem. Trop. Pest Manage. 36: 305-309.

Shelly, T. E., E. Pahio and J. Edu (2004) Synergistic and inhibitory interactions between methyl eugenol and cue lure influence trap catch of male fruit flies, Bactrocera dorsalis (Hendel) and B. cucurbitae (Diptera: Tephritidae). Fla. Entomol. 87: 481-486.

Smith, P. H. (1989) Behavioral partitioning of the day and circadian rhythmicity. In World Crop Pests. Vol. 3(B). Fruit Flies: Their Biology, Natural Enemies and Control (A. S. Robinson and G. Hooper eds.). Elsevier, Amsterdam, Netherlands, pp. 325-341.

Stark, J. D., R. I. Vargas and R. K. Thalman (1990) Azadirachtin: effects on metamorphosis, longevity, and reproduction of three tephritid fruit fly species (Diptera: Tephritidae). J. Econ. Entomol. 83: 2168-2174. 
Vargas, R. I., H. B. C. Chang, M. Komura and D. Kawamoto (1987) Mortality, stadial duration, and weight loss in three species of mass-reared fruit fly pupae (Diptera: Tephritidae) held with and without vermiculite at selected relative humidities. J. Econ. Entomol. 80: 972-974.

Vargas, R. I., N. W. Miller and J. D. Stark (2003) Field trials of spinosad as a replacement for naled, DDVP, and malathion in methyl eugenol and cue-lure bucket traps to attract and kill male oriental fruit flies and melon flies (Diptera: Tephritidae) in Hawaii. J. Econ. Entomol. 96: $1780-1785$.

Wong, T. T. Y., M. M. Ramadan, J. C. Herr and D. O. McInnis (1992) Suppression of a Mediterranean fruit fly (Diptera: Tephritidae) population with concurrent parasitoid and sterile fly releases in Kula, Maui, Hawaii. $J$. Econ. Entomol. 85: 1671-1681. 